\title{
LINGUAGEM E TRAUMA NA ESCRITA DO TESTEMUNHO
}

\author{
Jaime Ginzburg \\ Universidade de São Paulo
}

\begin{abstract}
Resumo: Partindo do debate contemporâneo sobre escrita de testemunho, este estudo procura examinar alguns aspectos de sua especificidade que constituem desafios para a crítica literária, como o problema da relação com a violência e a expressão de setores excluídos da sociedade.
\end{abstract}

Palavras-chave: Testemunho; história; linguagem; violência.

\begin{abstract}
Considering contemporary discussion on testimony, this study tries to examine some of its specific elements, as challenges to Literary Criticism, such as the presence of violence and the expression of excluded social segments.
\end{abstract}

Keywords: testimony; history; language; violence.

$\mathrm{Na}$ tradição crítica brasileira, o debate sobre o valor estético de obras literárias envolve freqüentemente tensões, que motivam a reflexão sobre seus fundamentos. Os diálogos com os estudos literários lusófonos e hispano-americanos têm constantemente permitido abrir novos horizontes. Entre eles, está a demanda de discussão do conceito de testemunho.

Esse conceito tem ganho maior espaço, nos últimos anos, em estudos literários no Brasil. Podemos encontrá-lo em investigações sobre temas hispano-americanos, africanos e alemães. Esse crescimento não ocorre sem dificuldades e contradições. Não há consenso entre os teóricos do testemunho, em relação a como lidar com este conceito, conforme João Camillo Penna (PENNA: 2003, 322) e Gustavo V. García (GARCIA: 2003, 33). O campo tem crescido em torno do debate sobre as relações entre escrita e exclusão social (SELIGMANN-SILVA: 2007, 36).

O debate crítico sobre testemunho e literatura inclui desde posições amplamente favoráveis à valorização do testemunho, como a de James Hatley (HATLEY:2000), como ponderações incisivas, por exemplo, a de Beatriz Sarlo (SARLO: 2007). Enquanto para Hatley o interesse pelo testemunho se associa à responsabilidade social perante o passado, em Sarlo aparece a idéia de que o discurso de testemunho pode comprometer a interpretação da história. Em ambos os casos, o Holocausto alemão aparece como referência central de reflexão.

Encontramos a acepção literatura de testemunho em estudos dedicados a Primo Levi, referentes à Segunda Guerra Mundial. O termo foi apropriado pelos estudos latino-americanos, com referência a autores como Rigoberta Menchú, e recentemente, a expressão carcerária, em Luiz Alberto Mendes e André du Rap. Falamos em testemunho também para referir à escrita de resistência à colonização na África, como no caso de Pepetela.

Críticos dedicados a Levi, Menchú, Mendes e Pepetela têm em comum, ao falar em testemunho, uma perspectiva que associa diretamente o debate sobre a escrita à 
reflexão sobre exclusão social. Nesse sentido, discursos críticos que estabelecem separações rígidas entre a literatura e a história podem ser rediscutidos, em razão de uma integração necessária que o testemunho, como objeto de investigação, solicita entre os campos das duas disciplinas.

Para além disso, o estudo do testemunho articula estética e ética como campos indissociáveis de pensamento. O problema do valor do texto, da relevância da escrita, não se insere em um campo de autonomia da arte, mas é lançado no âmbito abrangente da discussão de direitos civis, em que a escrita é vista como enunciação posicionada em um campo social marcado por conflitos, em que a imagem da alteridade pode ser constantemente colocada em questão.

García considera a escrita de testemunho uma forma nova de criar literatura, em contrariedade à tradição canônica (GARCÍA: 2003, 12). Caracteriza sua especificidade uma conexão direta dos textos com a defesa de direitos civis, em contrariedade a autoritarismos institucionais. Relatos testemunhais surgem associados a abusos de Estado, em solidariedade a vítimas e em atenção crítica à violência (idem, 19-25).

A origem da noção de testemunho é jurídica, e remete etimologicamente à voz que toma parte de um processo, em situação de impasse, e que pode contribuir para desfazer uma dúvida. Além disso, o termo testemunho se associa na tradição com a figura do mártir, o sobrevivente de uma provação (SELIGMANN-SILVA: 2003, 378). Em ambas as condições, trata-se de indicar uma fala em tensão com uma realidade conflitiva.

A literatura de testemunho não se filia à concepção de arte pela arte. Ela vai reivindicar uma conexão com o mundo extraliterário (idem, 379). Teoricamente, nesse sentido, é importante examinar o caráter específico da configuração discursiva do testemunho. Estabelecendo dificuldades para abordagens e procedimentos convencionais da Teoria Literária, não estamos em um campo de entendimento da arte como representação, no sentido atribuído à mimese aristotélica.

A literatura de testemunho também não se filia aos ideários nacionalistas, tão importantes na historiografia canônica brasileira. Há uma relação direta entre ideologias nacionalistas e exclusão, e se trata no testemunho de atribuir voz a subalternos excluídos (PENNA: 2003, 317). O nacionalismo habitualmente elege uma concepção identitária fixa e unitária, deixando à margem segmentos tidos como inferiores ou perturbadores. $\mathrm{O}$ fato de que a voz testemunhal não se refere a uma generalidade universalizante, mas a uma posição específica, situa seu interesse político (idem, 324), em contrariedade ao autoritarismo. Fundamentalmente, o testemunho se coloca em oposição ao discurso oficial do Estado e às repressões institucionais (GARCÍA: 2003, 21).

O testemunho transgride os modos canônicos de propor o entendimento da qualidade estética, pois é parte constitutiva de sua concepção um distanciamento com relação a estruturas unitárias e homogêneas. Diferentemente, ele aponta para a dificuldade de narrar os acontecimentos (SELIGMANN-SILVA: 2003, 382). O narrador testemunhal pode ser examinado como um narrador em confronto com um senso de ameaça constante por parte da realidade.

O escritor Primo Levi nos oferece um paradigma fundamental do testemunho. Sendo sobrevivente de campos de concentração nazista, seus relatos guardam uma combinação de perplexidade e necessidade de fala. Como sobrevivente, Levi tem uma expressão em cujo fluir a linguagem é uma condição de ultrapassagem do contato com a morte. Seu trabalho está em um ponto tenso entre memória e esquecimento, uma vez que o reencontro com o que foi vivido pode trazer, em seu interior, um risco de repetição do sentimento de dor (idem, 52-3). Dar testemunho, em larga medida, consiste em relatar a proximidade da morte (SELIGMANN-SILVA: 2007, 52). 
A escrita do sobrevivente se vincula à memória daqueles que não sobreviveram. Nesse sentido, escrever é também uma forma de dar túmulo aos mortos, para que não sejam esquecidos (SELIGMANN-SILVA: 2003, 55). Para Jorge Semprun, é necessário para os sobreviventes de campos de concentração o registro ficcional, como condição de elaboração das vivências (idem, 384).

Rigoberta Menchú recebeu em 1992 o Prêmio Nobel da Paz, associado ao testemunho Meu nome é Rigoberta Menchú e assim me nasceu a consciência. Seu trabalho se refere a problemas indígenas e agrícolas na Guatemala (PENNA: 2003, 301). O testemunho sobre genocídio indígena aponta para a necessidade de pensar a relação da escrita com o processo colonizador, a partir de uma perspectiva que problematiza o lugar de onde fala o sujeito da enunciação. Para João Camillo Penna, o interesse da crítica literária pelo testemunho hispano-americano está ligado a uma solidariedade com relação às atrocidades em guerras civis e repressão na América Latina.

O nascimento do testemunho latino-americano remonta à Revolução Cubana, e articula sujeitos de enunciação, nos termos de João Camillo Penna, tradicionalmente "silenciados e subjugados" (idem, 302-3). O testemunho se vincula, nesse sentido, a movimentos de resistência. Sua compreensão exige perceber uma vida política dotada de multicentralidade. Nessa perspectiva, um indivíduo não é entendido em uma concepção burguesa, e sua constituição não se restringe a determinações nacionais. $\mathrm{O}$ texto de testemunho é necessariamente vinculado com vivências de um grupo de vítimas, do qual o sujeito da enunciação é um articulador. O sujeito é constituído não a partir de uma auto-suficiência interna, mas pelo contrário, de cruzamentos de múltiplas forças externas (idem,

304).

No caso latino-americano, diferentemente do alemão, estamos lidando com "culturas com uma inserção precária no universo escrito". Com a expressão de culturas e subjetividades emergentes, o testemunho entra em confluência com a antropologia (idem, 307). Maria Rita Palmeira observa um traço semelhante em relatos carcerários, em que à palavra é atribuído um papel decisivo em "um universo pouco letrado" (PALMEIRA: 2007, 65).

$\mathrm{O}$ estudo do testemunho exige uma concepção da linguagem como campo associado ao trauma. A escrita não é aqui lugar dedicado ao ócio ou ao comportamento lúdico, mas ao contato com o sofrimento e seus fundamentos, por mais que sejam, muitas vezes obscuros e repugnantes. $\mathrm{O}$ século $\mathrm{XX}$ se estabeleceu como tempo propício para testemunho, em virtude da enorme presença das guerras e dos genocídios. Para o sujeito da enunciação do testemunho, entre o impacto da catástrofe e os recursos expressivos, pode haver um abismo intransponível, de modo que toda formulação pode ser imprecisa ou insuficiente.

A constituição de uma tendência de produção de escrita pautada na exclusão é fato que exige reflexão de teóricos da literatura. Isso é particularmente ostensivo, quando o objeto estabelece desafios em escala histórica. Em um caso de uma sociedade que não tem uma produção historiográfica suficiente em proporção às necessidades de consciência reflexiva, em que o próprio discurso histórico merece atenção cuidadosa, o interesse por escritores pode ter uma função particularmente decisiva.

Com relação a Angola, cabe destacar o trabalho de Isabelita Maria Crosariol. A autora destaca, em sua reflexão em torno de Pepetela, a violência histórica presente na colonização portuguesa. A sociedade angolana não teria conseguido escrever sua história, em razão do impacto da violência colonial (CROSARIOL: 2007, 120).

Com o testemunho, é elaborada uma perspectiva para a compreensão do passado a partir dos excluídos. É estabelecido nesse ponto um dilema, referente à língua a ser 
escolhida. Um impasse aflora quando é necessário, por esforço de preservação de memória e difusão do material, utilizar a língua do colonizador para realizar o testemunho (idem, 123).

No Brasil, um caso estudado por Márcio Seligmann-Silva, apontado como dotado de forte teor testemunhal, é a escrita de Luiz Alberto Mendes. Construído como relato de vivências prisionais, o livro de Mendes integra o impacto da repressão política brasileira e os horrores do interior do mundo carcerário. Com a escrita, Mendes alcança apresentar uma perspectiva do que vivenciou calcada na dor do corpo (SELIGMANNSILVA: 2007, 41).

Trata-se de um relato de duplo interesse, pois remete à margem da sociedade e ao princípio da legislação brasileira, ao discutir a interdição e a condenação. A partir de um microcosmo, percebemos "a estrutura violenta da sociedade" brasileira (idem, 44). Nesse livro, a violência envolve manifestações sobre sexualidade, em razão da problematização das referências de virilidade no campo do poder no cárcere (idem, 45).

Em um ambiente de práticas de tortura e exposição continuada do corpo à dor, Mendes compara sua condição à das vítimas do nazismo (idem, 49). Isso chama a atenção, pois temos duas situações históricas diferentes, aproximadas pelo impacto violento associado à fala testemunhal.

Maria Rita Palmeira estudou o caso de André du Rap, e verificou que entre os relatos carcerários ocorre que os expositores "mostravam-se, como os sobreviventes dos campos de extermínio, incapazes de dar conta do momento doloroso e indescritível" (PALMEIRA: 2007, 61). O escritor faz referência ao Massacre do Carandiru, com dificuldade de narrar o que vivenciou, como se fosse um Holocausto (idem, 67-8).

A escrita do testemunho não se restringe ao depoimento direto, mas deve passar por elaboração atenta dos recursos de linguagem escolhidos. Um real traumático exposto pode não ser compreendido, e ainda, não ser aceito, quando seu impacto é intolerável. A configuração discursiva pode aumentar a capacidade de preservar o teor do que foi vivido junto à memória do público. A memória do testemunho desconstrói a história oficial, e a presença do estético pode cumprir um papel ético (SELIGMANNSILVA: 2003, 57). Se o acabamento formal, com recursos de estilização literária, permitir atribuir ao testemunho um efeito mais incisivo na contrariedade ao discurso hegemônico, o valor ético da narração pode justificar a incorporação de componentes artísticos.

O valor do testemunho não está na sua capacidade de ser comprovado, como se fosse posto à prova em termos científicos (GARCÍA: 2003, 44). De acordo com Márcio Seligmann-Silva, a base do testemunho consiste em uma ambigüidade: por um lado, a necessidade de narrar o que foi vivido, e por outro, a percepção de que a linguagem é insuficiente para dar conta do que ocorreu (SELIGMANN-SILVA: 2003, 46). A identidade do sujeito da enunciação é apresentada como objeto perdido, e o discurso, um esforço de elaboração (PENNA: 2003, 312). Sem identidade segura, a voz de enunciação faz da narração a busca de um sentido que não foi antecipadamente definido.Trata-se de um discurso instável, híbrido, em que os conflitos sociais são incorporados aos fundamentos expressivos (GARCÍA: 2003, 50).

$\mathrm{O}$ conceito de real é especificamente problematizado, quando pensamos em testemunho. Não estamos diante de uma percepção do senso comum. A vítima do testemunho não vê apenas o que é trivialmente aceito. $\mathrm{O}$ que merece testemunho, em princípio, é caracterizado por uma excepcionalidade, e exige ser relatado (SELIGMANN-SILVA: 2003, 47). O real é entendido como traumático. Para Penna, "o testemunho fala e narra o nosso encontro com o Real do trauma, assim como concebido por Lacan, o encontro com estas experiências do corpo que sofre" (PENNA: 2003, 347). 
Quando a dor corporal é incontornável, ocorre "uma espécie de descolamento entre mente e corpo: ou seja, vontade de abandonar o corpo" (SELIGMANN-SILVA: 2007, $53)$.

Em um corpo sofrido, a relação entre língua e pensamento é abalada pela negatividade da experiência. A linguagem é percebida como traço indicativo de uma lacuna, de uma ausência. A experiência traumática não pode ser, para a psicanálise, assimilada de modo completo; por isso, ocorre a repetição constante, alucinatória, por parte da vítima, da cena de impacto (SELIGMANN-SILVA: 2003, 48-9).

Em uma elaboração do trauma, a forma artística é atingida, e os condicionamentos canônicos são relativizados. Isso é observado, por exemplo, na comparação do romance realista oitocentista com o testemunho. Como explica João Camillo Penna, o gênero romance estava articulado, em sua formação, com os processos históricos de formação do capitalismo. Esses processos envolveram, para a acumulação, o impulso colonizador. O testemunho latino-americano se coloca contra o impacto agressivo da história de colonização, e com isso, contraria também os fundamentos estéticos do romance burguês (PENNA: 2003, 332).

Segundo Penna, em Barnet, por exemplo, não há ênfase na função referencial da linguagem, nem expectativa de cumprir procedimentos de uma estética realista. Isto é, os fundamentos necessários para uma representação, no sentido tradicional da mimese, cedem a uma inclinação "representativa (no sentido político do termo)" (idem, 310). Em Palmeira também é observada a problematização, nos relatos carcerários, dos limites da representação (PALMEIRA: 2007, 75).

Penna explica ainda que "o testemunho não pode ser entendido a partir da categoria do realismo, pois tem como vocação mais essencial a sua exterioridade com relação à imitação (...) Todo o problema da referencialidade, que o testemunho divide com o realismo, será recolocado em termos de uma prática dos movimentos sociais, na qual a forma literária estaria inscrita" (PENNA: 2003, 338).

A imagem da experiência não é de uma totalidade social, mas de uma "totalidade relativa, fragmentária" (idem, 314). O testemunho pede a elaboração de um novo conceito de representação, ligado ao estabelecimento de identidades políticas (idem, 314). É necessário diferenciar narrativas que postulam uma experiência "individual e particular", na autobiografia tradicional, e "a formação de uma subjetividade coletiva do testemunho" (idem, 318). Palmeira observa, no caso dos relatos de cárcere, esse componente coletivo no discurso (PALMEIRA: 2007, 71). Embora apartados da sociedade, os prisioneiros expõem comprometimento com valores coletivos (idem, 74). Como explica García, "Indígenas, mulheres operárias, camponeses, donas de casa, homossexuais, exilados e outros, por meio do testemunho, convertem o livro, instrumento de cultura, em arma de libertação e defesa de direitos" (GARCÍA: 2003, 33).

Em um tempo de catástrofes, o trauma é impregnado no cotidiano, com a difusão do choque na modernidade (SELIGMANN-SILVA: 2003, 49). O trauma resiste à representação, e por isso é redimensionada a apropriação do termo literatura pelo discurso crítico, quando se trata de testemunho: trata-se de dar voz a vítimas do impacto do trauma, e também apresentar uma posição campo de conflitos históricos (idem, 387). O testemunho é necessário, nesse sentido, em contextos políticos e sociais em que a violência histórica foi muito forte, desempenhando papel decisivo na constituição das instituições. Nesses contextos, as diferenças de perspectiva entre os setores em conflito implicam em diferenças formais e temáticas nas concepções de escrita e em seus recursos institucionais de legitimação. 
A pesquisa do testemunho caminharia para uma politização da estética, em um mundo tomado pela estetização da política (PENNA: 2003, 306). Estudar o testemunho significa assumir que aos excluídos cabe falar, e além disso, definir seus próprios modos de fazê-lo.

\section{REFERÊNCIAS BIBLIOGRÁFICAS}

CROSARIOL, Isabelita Maria. O testemunho na literatura angolana: uma reescrita da história em tempos de violência. Gandara. Rio de Janeiro, 2007.

GARCÍA, Gustavo V. La literatura testimonial latinoamericana. Madrid: Pliegos, 2003.

HATLEY, James. Suffering witness. New York: State University of New York, 2000.

LEVI, Primo. Os afogados e os sobreviventes. Rio de Janeiro: Paz e Terra, 1990.

MENCHU, Rigoberta. I, Rigoberta Menchú. An Indian Woman in Guatemala. New York: Verso, 1984.

MENDES, Luiz Alberto. Memórias de um sobrevivente. São Paulo: Companhia das Letras, 2001.

PALMEIRA, Maria Rita. Cada história, uma sentença: anotações sobre Sobrevivente André du Rap. Estudos de literatura brasileira contemporânea. Brasília, 2007. n.27.

PENNA, João Camillo. Este corpo, esta dor, esta fome: notas sobre o testemunho hispanoamericano. In: SELIGMANN-SILVA, Márcio, org. História, memória, literatura. Campinas: Ed. Unicamp, 2003.

PEPETELA. A geração da utopia. Lisboa: Dom Quixote, 2000.

RAP, André du. Sobrevivente André du Rap (do Massacre do Carandiru). São Paulo: Labortexto, 2002.

SARLO, Beatriz. Tempo passado. São Paulo: Companhia das Letras, 2007.

SELIGMANN-SILVA, Márcio. Apresentação da questão. In: __, org. História, memória, literatura. Campinas: Ed. Unicamp, 2003.

SELIGMANN-SILVA, Márcio. Novos escritos dos cárceres: uma análise de caso. Luiz Alberto Mendes, Memórias de um sobrevivente. Estudos de literatura brasileira contemporânea. Brasília, 2007. n.27.

SELIGMANN-SILVA, Márcio. O testemunho: entre a ficção e o real. In: org. História, memória, literatura. Campinas: Ed. Unicamp, 2003. 